\title{
Penentuan Injeksi Udara Optimum dalam Operasi Aerated Drilling pada Sumur Panas Bumi PT. Air Drilling Associates
}

\author{
Rial Dwi Martasari ${ }^{(1, a) *}$, Dany Wiratama ${ }^{(1)}$ dan Dwi Arifiyanto ${ }^{(1)}$ \\ ${ }^{(1)}$ Prodi Diploma-III Teknik Perminyakan, Akademi Minyak dan Gas Balongan, Indramayu, Indonesia, 45216 \\ Email: ${ }^{\left(a^{*}\right)}$ rialdwim@gmail.com
}

Diterima (12 November 2021), Direvisi (31 Desember 2021)

\begin{abstract}
Drilling success is an important factor in developing a geothermal field. In the project of drilling, circulation system requiring considerable cost considering the challenges in geothermal drill which will be facing a very high temperature. It is important to choose drilling fluid which will give best consideration in terms of cost, safety, reaching the desired depth and output from the wells. Drilling with aerated fluid is a balance drilling technique approaching underbalance. Aerated drilling technique is done by adding compressed air into the drilling fluid (mud or water). This aeration drilling fluid density is effective between 5-7 ppg. Determination of the range of the volume of air injection into mud circulation is made to know the Equivalent Circulating Density (ECD) for effective operation of aerated drilling in geothermal drilling. Testing done in simulation of drilling geothermal wells on aeration with section $121 / 4$ " at a depth of 2180 metres, section 95/8 " in depth of 2530 meters and section 7 7/8 "in the depths of where in that zone there is partial loss and the use of the ratio of the volume of injection of mud and air varies with each route. For example, on a 12 1/4" route, the mud volume is $600 \mathrm{gpm}$ with an air volume of $500 \mathrm{scfm}$. At a mud volume of $700 \mathrm{gpm}$ with an air volume of $500 \mathrm{scfm}$ and $1000 \mathrm{scfm}$. At a mud volume of $800 \mathrm{gpm}$ with an air volume of $1000 \mathrm{scfm}$. At $900 \mathrm{gpm}$ mud volume, the recommended air volume is $1000 \mathrm{scfm}$.
\end{abstract}

Keywords: Geothermal, Aerated Drilling, Air Injection.

Abstrak. Kesuksesan pengeboran adalah faktor penting dalam mengembangkan bidang panas bumi. Dalam proyek pengeboran, sistem sirkulasi membutuhkan biaya yang cukup besar mengingat tantangan mengebor di panas bumi yang akan menghadapi temperature yang sangat tinggi. Penting untuk memilih fluida pemboran yang akan memberikan pertimbangan terbaik dalam hal biaya, keselamatan, mencapai kedalaman yang diinginkan dan output dari sumur. Pengeboran dengan aerated fluid adalah teknik pengeboran balance mendekati underbalance. Teknik pengeboran aerated dilakukan dengan menambahkan kompresi udara ke fluida pemboran (lumpur atau air). Fluida pemboran aerasi ini memiliki densitas efektif antara 5-7 ppg. Penentuan rentang volume injeksi udara ke dalam sirkulasi lumpur dibuat untuk mengetahui Equivalent Circulating Density (ECD) yang efektif untuk operasi aerated drilling pada pemboran panas bumi. Pengujian dilakukan dalam simulasi pemboran aerasi pada sumur geothermal dengan trayek $121 / 4$ " di kedalaman 2180 meter, trayek $95 / 8$ " di kedalaman 2530 meter dan trayek 7 7/8 “ di kedalaman 2950 meter dimana pada zona tersebut terdapat partial loss dan penggunaan perbandingan volume injeksi lumpur dan udara bervariasi setiap trayek. Sebagai contoh pada trayek 12 1/4 " yaitu Pada volume lumpur 600 gpm dengan volume udara $500 \mathrm{scfm}$. Pada volume lumpur $700 \mathrm{gpm}$ dengan volume udara $500 \mathrm{scfm}$ dan 1000 scfm. Pada volume lumpur $800 \mathrm{gpm}$ dengan volume udara $1000 \mathrm{scfm}$. Pada volume lumpur $900 \mathrm{gpm}$, volume udara yang direkomendasikan yaitu $1000 \mathrm{scfm}$.

Kata kunci: Aerated Drilling, Injeksi Udara, Panas Bumi. 
Rial Dwi Martasari : Penentuan Injeksi Udara Optimum dalam Operasi Aerated Drilling pada Sumur

Panas Bumi PT Air Drilling Associates

Jurnal Migasian, e-issn: 2615-6695 / p-issn: 2580-5258

\section{PENDAHULUAN}

Energi panas bumi merupakan energi panas alami dari dalam bumi yang ditransfer ke permukaan bumi secara konduksi dan konveksi. Pada sumur panas bumi, jenis batuan yang sering dijumpai di sumur panas bumi ini adalah batuan beku. Batuan yang keras ini akan mempengaruhi peralatan pemboran dan tingkat penembusan pemboran, sehingga dibutuhkan sesuatu yang dapat menjaga stabilitas pemboran. Terdapat dua tantangan utama dalam pemboran sumur panas bumi sekaligus yang membedakannya dari pemboran di sumur minyak dan gas, yaitu dalam hal temperature formasi dan formasi yang lebih banyak fracture. Loss circulation terjadi karena target dalam suatu sumur panas bumi merupakan rekahan-rekahan (fracture) yang terkoneksi ke suatu heat source. Ketika rekahan tersebut terlewati dalam proses pemboran, kemungkinan besar lumpur pemboran akan masuk ke dalam rekahan-rekahan tersebut dan tidak kembali ke permukaan (loss circulation). Oleh sebab itu diperlukan perencanaan lumpur pemboran yang mampu menunjang suksesnya pemboran panas bumi terutama ketika menembus zona loss yang tentunya membutuhkan lumpur khusus yang mumpuni untuk digunakan pada sumur panas bumi yang berbeda dengan sumur minyak bumi.

Pada dasarnya sistem panas bumi terbentuk sebagai hasil perpindahan panas dari suatu sumber panas ke sekelilingnya yang terjadi secara konduksi dan secara konveksi. Perpindahan panas secara konduksi terjadi melalui batuan, sedangkan perpindahan panas secara konveksi terjadi karena adanya kontak antara air dengan suatu sumber panas. Terjadinya sumber energi panas bumi di Indonesia serta karakteristiknya terdapat tiga lempengan yang berinteraksi di Indonesia, yaitu lempeng Pasifik, lempeng IndiaAustralia dan lempeng Eurasia. ${ }^{[4]}$ Tumbukan yang terjadi antara ketiga lempeng tektonik tersebut telah memberikan peranan yang sangat penting bagi terbentuknya sumber energi panas bumi di Indonesia. Tumbukan antara lempeng India-Australia di sebelah selatan dan lempeng Eurasia di sebelah utara menghasilkan zona penunjaman (subduksi).

Lumpur pemboran merupakan faktor yang penting dalam pemboran. Kecepatan pemboran, efisiensi, keselamatan dan biaya pemboran sangat tergantung pada lumpur ini. Fungsi lumpur antara lain adalah untuk mengontrol tekanan subsurface dengan memberikan tekanan hidrostatik (Ph) lebih besar dari tekanan formasi (Pf), untuk membersihkan lubang dari cuttings, untuk mendinginkan dan melumasi bit dan drill string, membuat dinding pada lubang pemboran dengan mud cake, untuk mencegah dinding lubang sumur dari caving dan untuk pengangkatan cuttings ke permukaan [2]. Lumpur pemboran dapat diklasifikasikan berdasarkan fasanya, terdapat 3 tipe yaitu water based mud, oil based mud dan gas based mud [2].

Dalam pemboran sumur panas bumi terdapat bermacam-macam metode yang dilakukan, salah satu diantaranya adalah aerated drilling. Metode ini diadaptasi dari teknik air drilling dan foam drilling yang digunakan di pemboran sumur minyak. Metode aerated drilling pertama kali ditemukan oleh sebuah tim dari Selandia Baru dan sejak pertama kali ditemukan teknik ini memberikan hasil yang sangat baik dalam perolehan output sumur. Lumpur aerated drilling mempunyai densitas yang kecil dibandingkan dengan lumpur pemboran konvensional, tekanan hidrostatik di dalam lubang pemboran lebih rendah dari tekanan formasi. Penggunaan 
lumpur aerated drilling mengurangi terjadinya loss circulation [3].

Tujuan dilakukannya penelitian ini adalah evaluasi aerated drilling pada trayek 12-1/4“, 9-5/8 " dan 7-7/8 “ guna mengetahui perbandingan volume injeksi udara yang direkomendasikan pada trayek 12-1/4“, 9-5/8" dan 7-7/8.

\section{METODE PENELITIAN}

Untuk mendukung penelitian dan kajian yang akan dilakukan sehingga dapat ditarik suatu kesimpulan, maka dapat dilakukan beberapa metode pelaksanaan (Gambar 1), yaitu antara lain :

1. Study Literature adalah mencari referensi-referensi yang berhubungan dengan pemboran yang menggunakan metode aerated drilling dari tempat penelitian maupun dari literatur-literatur lain. Berikut adalah literatur yang digunakan dalam pengumpulan data informasi: buku Boyun Guo, Sun Kai dan report perusahaan. Serta bahan tambahan dalam penyusunan penelitian yang berkaitan dengan topik.

2. Pengambilan data dilakukan terlebih dahulu sebelum memulai pengujian data, data tersebut merupakan data aktual formasi dan data asumsi (true vertical depth, diameter pipa dan bit, gravity, fluid density, air injection rate dan fluid injection rate).

3. Pengolahan data dilakukan dengan melakukan perhitungan aerasi yaitu proses data pemboran yang telah ditentukan yaitu Equivalent Circulating Density (ECD) dan bottom hole circulating pressure (BHCP).

4. Hasil Analisa merupakan kegiatan menganalisa perhitungan $\mathrm{BHCP}$ dan ECD yang dipadukan dengan injeksi udara dan injeksi lumpur sehingga goals dari penelitian ini terdapat pada hasil injeksi udara yang sesuai digunakan pada setiap trayek.

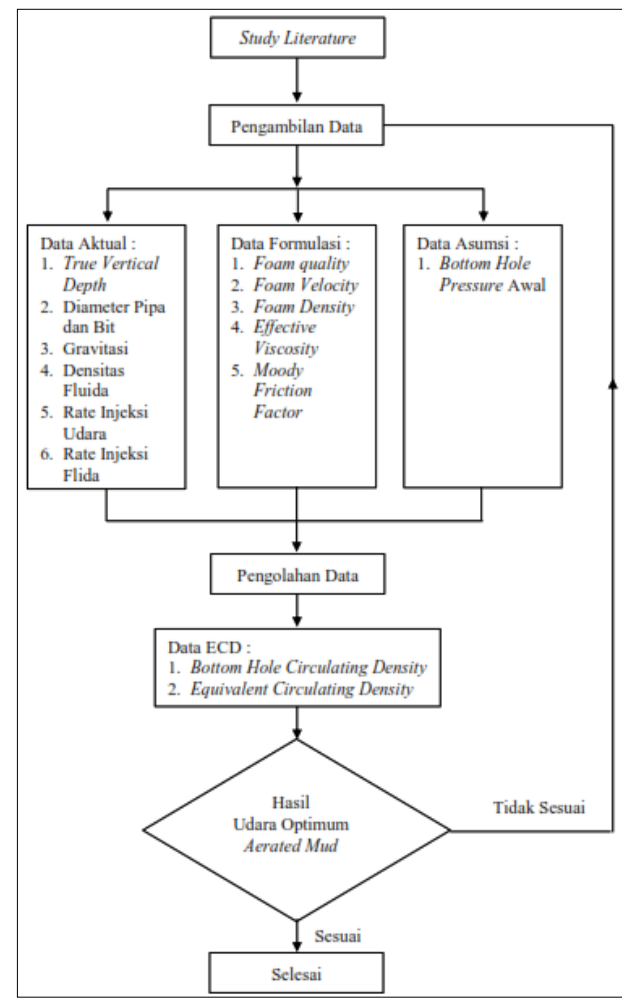

Gambar 1. Flow Chart

\section{HASIL DAN PEMBAHASAN}

\section{Data}

Sumur ini rencananya akan dibor vertikal dengan total kedalaman $2950 \mathrm{~m}$ (Gambar 2). Zona rekah total dan partial diprediksi akan dialami pada kedalaman $2180 \mathrm{~m}, 2530 \mathrm{~m}$ dan $2950 \mathrm{~m}$. Aerated drilling akan digunakan pada section 12 1/4“, 95/8 " dan 7 7/8 " dengan tujuan dapat menangani loss yang terjadi pada section tersebut (Tabel 1), namun rentang penggunaan udara belum ditentukan. Penentuan rentang penggunaan udara ini sangat kritikal untuk menentukan kesuksesan pemboran hingga target kedalaman sumur. 
Rial Dwi Martasari : Penentuan Injeksi Udara Optimum dalam Operasi Aerated Drilling pada Sumur Panas Bumi PT Air Drilling Associates

Jurnal Migasian, e-issn: 2615-6695 / p-issn: 2580-5258

Tabel 1. Data Perhitungan Aerated Drilling

\begin{tabular}{|c|c|c|c|}
\hline \multirow{2}{*}{ Parameter } & \multicolumn{3}{|c|}{ Trayek } \\
\hline & $12 \frac{1}{4}$ & $9 \frac{5}{8}$ & $7 \frac{7}{8}$ \\
\hline TVD (ft) & 7152.23 & 8300.52 & 9678.48 \\
\hline Inklinasi & 0 & 0 & 0 \\
\hline Temperature Sirkulasi $\left({ }^{0} \mathrm{R}\right)$ & 599.65 & 614.07 & 617.67 \\
\hline Temperature Surface $\left({ }^{\mathbf{0}} \mathrm{R}\right)$ & 549.27 & 558.27 & 563.67 \\
\hline Diameter Bit (inch) & $12 \frac{1}{4}$ & $9 \frac{5}{8}$ & $7 \frac{7}{8}$ \\
\hline Diameter Inside DP (inch) & 5 & 5 & 5 \\
\hline Diameter Liner (inch) & $10 \frac{3}{4}$ & $8 \frac{5}{8}$ & 7 \\
\hline MW (ppg) & 8.5 & 8.4 & 8.4 \\
\hline Pf (psi) & 3096.92 & 3594.13 & 4190.78 \\
\hline Asumsi Udara (SCFM) & $\begin{array}{c}100,500,1000,1500, \\
2000,2400\end{array}$ & $\begin{array}{c}100,500,1000,1500 \\
2000,2400\end{array}$ & $\begin{array}{c}100,500,1000,1500, \\
2000,2400\end{array}$ \\
\hline Asumsi Lumpur (GPM) & $600,700,800,900$ & $500,600,700,800$ & $400,500,600,700$ \\
\hline
\end{tabular}

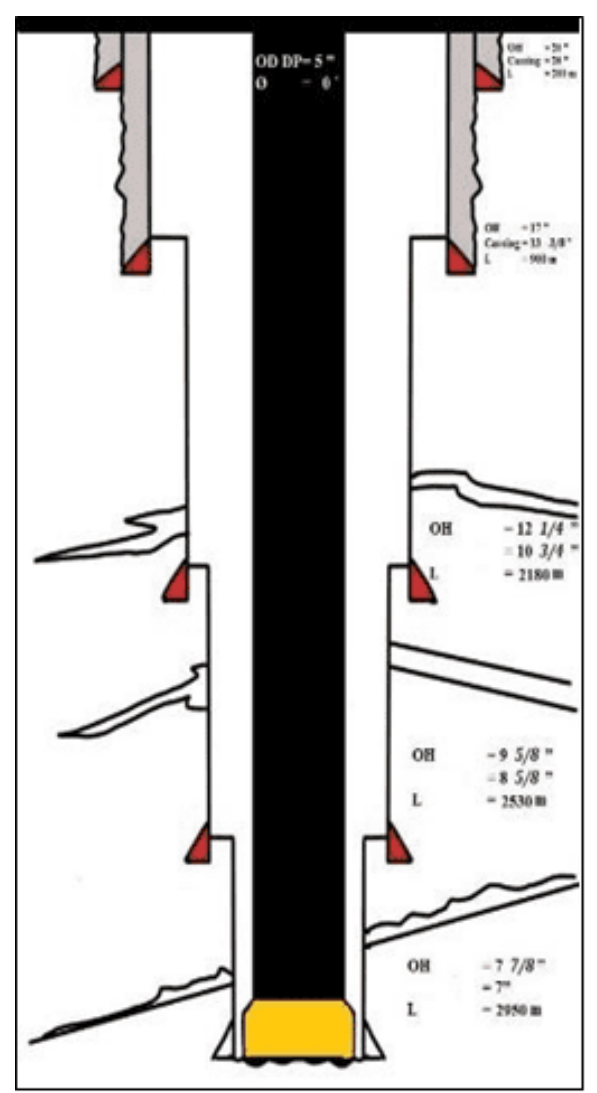

Gambar 2. Profil sumur
Tahapan Pencarian Perbandingan

\section{Lumpur dan Udara}

1. Menghitung BHCP

a. Perhitungan Tekanan Hidrostatik (Ph)

Perhitungan akan diwakili dengan data sumur trayek $12 \frac{16}{4}$, pada rate injeksi lumpur 600 gpm dan rate injeksi udara 500 scfm (Tabel 2).

$$
\begin{aligned}
\mathrm{Ph} & =0.052 \times \rho f \times \text { TVD } \\
& =0.052 \times 8.5 \times 7152.23 \\
\mathrm{Ph} & =3161.29 \mathrm{psi}
\end{aligned}
$$

Tabel 2. Hasil Tekanan Hidrostatik

\begin{tabular}{lccc}
\hline \multirow{3}{*}{ Parameter } & \multicolumn{3}{c}{ Trayek } \\
\cline { 2 - 4 } & $12 \frac{1}{4}$ & $9 \frac{5}{8}$ & $7 \frac{7}{8}$ \\
\hline Ph (psi) & 3161.29 & 3625.67 & 4227.56 \\
\hline
\end{tabular}




\section{b. Menghitung Gas Liquid Ratio (GLR)}

Perhitungan akan dilakukan pada rate injeksi lumpur $600 \mathrm{gpm}$ dan rate injeksi udara $500 \mathrm{scfm}$.

$$
\begin{aligned}
\text { GLR } & =\frac{\mathrm{Q}_{g o}}{\mathrm{Q}_{1}} \\
& =\frac{500}{600} \\
\text { GLR } & =0.83
\end{aligned}
$$

Keterangan :

$\mathrm{Q}_{\mathrm{go}}=$ Rate injeksi udara

$\mathrm{Q}_{1}=$ Rate injeksi liquid

\section{c. Menghitung GLR Maximum}

Agar foam tetap stabil selama pemboran maka Formation fluid influx rate $\left(\mathrm{Q}_{\mathrm{fx}}\right)$ harus dikontrol antara $0.55-0.97$ (digunakan dalam perhitungan 0.97), maka perhitungan GLR Max :

$$
\begin{aligned}
\text { GLR }_{\text {Max }} & =\frac{\Gamma_{\max }}{1-\Gamma_{\max }}\left(0.13369+0.09358 \frac{Q_{\text {fx }}}{Q_{1}}\right) \\
& =\frac{0.97}{1-0.97}\left(0.13369+0.09358 \frac{0}{600}\right) \\
& =4.32
\end{aligned}
$$

\section{d. Menghitung Foam Quality}

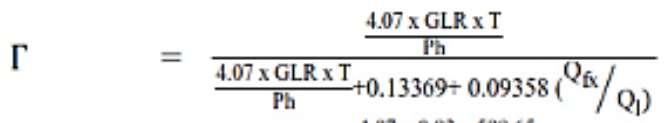

$$
\begin{aligned}
& \Gamma=\frac{4.07 \times 0.83 \times 599.65}{3161.29} \\
& \Gamma=0.04
\end{aligned}
$$

\section{e. Perhitungan Foam Quality at Choke}

$$
\begin{aligned}
\frac{\mathrm{Ph}}{\mathrm{Ps}} & =\frac{(\mathrm{T} \times \Gamma \mathrm{s}) \times(1-\Gamma)}{(\mathrm{Ts} \times \Gamma) \times(1-\Gamma \mathrm{s})} \\
\frac{3161.29}{50} & =\frac{(599.65 \times 0.8) \times(1-0.04)}{(549.27 \times 0.04) \times(1-0.8)} \\
49.52 & =102.35
\end{aligned}
$$

Setelah di Goal Seek, perbandingannya menjadi sama :

$$
49.52=49.52
$$

Didapat foam quality at choke sebesar :

Гs $\quad=0.66$ f. Perhitungan Hydraulic Diameter of Flow Path

$$
\begin{aligned}
\mathrm{D}_{\mathrm{H}} & =\left(\mathrm{OH}-\mathrm{OD}_{\mathrm{DP}}\right) \times 0.0833 \\
& =(12.25-5) \times 0.0833 \\
\mathrm{Ph} & =0.60 \mathrm{ft}
\end{aligned}
$$

g. Menghitung Cross Sectional Area of Flow Path

$$
\begin{aligned}
A & =3.14 \times\left(\frac{(\mathrm{OH})^{2}-(\mathrm{OD} p \mathrm{pP})^{2}}{4}\right) \\
& =3.14 \times\left(\frac{(12.25)^{2}-(5)^{2}}{4}\right) \\
\mathrm{A} & =98.17 \mathrm{in}^{2}
\end{aligned}
$$

\section{h. Perhitungan Effective Viscosity $\left(\boldsymbol{\mu}_{\mathrm{e}}\right)$}

Untuk mencari effective viscosity dapat menggunakan rumus dari rumus. ${ }^{[1]}$

$$
\begin{aligned}
& \mathrm{K}=-0.15626+56.147 \Gamma-312.77 \Gamma^{2}+ \\
& 576.65 \Gamma^{3}+63.960 \Gamma^{4}-960.46 \Gamma^{5} \\
& -154.68 \Gamma^{6}+1670.2 \Gamma^{7}-937.88 \Gamma^{8} \\
& =-0.15626+(56.147 \times 0.04)- \\
& \left(312.77 \times 0.04^{2}\right)+(576.65 \times \\
& \left.0.04^{3}\right)+\left(63.960 \times 0.04^{4}\right)- \\
& \left(960.46 \times 0.04^{5}\right)-(154.68 \times \\
& \left.0.04^{6}\right)+\left(1670.2 \times 0.04^{7}\right)- \\
& \left(937.88 \times 0.04^{8}\right) \\
& \mathrm{K}=1.66 \\
& n=0.095932+2.3654 \Gamma-10.467 \Gamma^{2}+ \\
& 12.955 \Gamma^{3}+14.467 \Gamma^{4}-14.467 \Gamma^{5} \\
& +20.625 \Gamma^{6} \\
& =0.095932+(2.3654 \times 0.04)- \\
& \left(10.467 \times 0.04^{2}\right)+(12.955 \times \\
& \left.0.04^{3}\right)+\left(14.467 \times 0.04^{4}\right)- \\
& \left(14.467 \times 0.04^{5}\right)+20.625 \times \\
& 0.04^{6} \text { ) } \\
& n=0.18
\end{aligned}
$$

Effective foam viscosity untuk foam quality dapat diestimasikan berdasarkan consistency index $\mathrm{K}$ dan flow behavior index $\mathrm{n}$ :

$$
\begin{aligned}
\mu_{\mathrm{e}} & =\mathrm{K}\left(\frac{2_{\mathrm{n}}+1}{3_{\mathrm{n}}}\right)^{\mathrm{n}}\left(\frac{12 \times \mathrm{v}_{\mathrm{f}}}{\mathrm{D}_{\mathrm{H}}}\right)^{\mathrm{n}-1} \\
& =1.66 \times\left(\frac{(2 \times 0.18)+1}{3 \times 0.18}\right)^{0.18}\left(\frac{12 \times 11.21}{0.60}\right)^{0.18-1} \\
\mu_{\mathrm{e}} & =0.02 \mathrm{lb} / \mathrm{ft}-\mathrm{s}
\end{aligned}
$$


Rial Dwi Martasari : Penentuan Injeksi Udara Optimum dalam Operasi Aerated Drilling pada Sumur Panas Bumi PT Air Drilling Associates

Jurnal Migasian, e-issn: 2615-6695 / p-issn: 2580-5258

i. Menghitung Average Foam Density $\left(\boldsymbol{\gamma}_{\mathrm{fa}}\right)$

$$
\begin{aligned}
\gamma_{\mathrm{fa}} & =\gamma_{1}-\left(\gamma_{1}-\left(\frac{\mathrm{s}_{\mathrm{g}} \times P_{\mathrm{h}}}{53.3 \times \mathrm{T}}\right)\right) \times \Gamma \\
& =63.58-\left(63.58-\left(\frac{1 \times 3161.29}{53.3 \times 599.65}\right)\right) \times 0.04 \\
\gamma_{\mathrm{fa}} & =61.43 \mathrm{lb} / \mathrm{ft}^{3}
\end{aligned}
$$

\section{j. Perhitungan Foam Velocity $\left(V_{f}\right)$}

$$
\begin{aligned}
V_{f} & =\left(\frac{Q_{1} \times Q_{\text {go }} \times Q_{\mathrm{fx}}}{\mathrm{A}}\right) \\
& =\left(\frac{600 \times 500 \times 0}{98.17}\right) \\
\mathrm{V}_{\mathrm{f}} & =11.21 \mathrm{fps}
\end{aligned}
$$

\section{k. Menghitung Friction Factor}

$$
\begin{aligned}
f & =\frac{64}{\operatorname{Re}}{ }_{64} \\
& =\frac{64}{18248.65} \\
f & =0.0035
\end{aligned}
$$

\section{l. Menghitung BHCP}

Untuk mencari BHCP dapat menggunakan perhitungan. ${ }^{[5]}$

$$
\begin{aligned}
b & =\frac{1 \cdot \Gamma_{s}}{P_{s} \times \Gamma_{s}} \\
& =\frac{1-0.66}{50 \times 0.66} \\
b & =0.00007 \\
a & =\frac{53.3 \times b \times \gamma_{1} \times T+S_{z}}{53.3 \times T} \times \cos (\theta) \\
& =\frac{53.3 \times 0.00007 \times 63.58 \times 599.65+1}{53.3 \times 599.65} \times \cos 0 \\
a & =0.00459 \\
c & =\frac{144 \times P_{s} \times T}{60 \times A \times T_{s}} \\
& =\frac{144 \times 50 \times 599.65}{60 \times 98.17 \times 549.27} \\
c & =192.17 \\
d & =\frac{144}{60 \times A}\left(\frac{Q_{1}}{7.48}+\frac{5.615 \times Q_{\mathrm{f}}}{60}\right) \\
& =\frac{144}{60 \times 98.17}\left(\frac{600}{7.48}+\frac{5.615 \times 0}{60}\right)
\end{aligned}
$$

$$
\begin{aligned}
d & =1.96 \\
e & =\frac{f}{2 \times g \times \mathrm{D}_{11} \times \cos (0)} \\
& =\frac{0.0035}{2 \times 32.2 \times 0.60 \times \cos 0} \\
e & =0.00009076 \\
N & =\frac{\mathrm{c}^{2} \times \mathrm{e}}{\left(1+\mathrm{d}^{2} \times \mathrm{e}\right)^{2}} \\
& =\frac{192.17^{2} \times 0.00009076}{\left(1+1.96^{2} \times 0.00009076\right)^{2}} \\
N & =3.35 \\
M & =\frac{\mathrm{c} \times \mathrm{d} \times \mathrm{e}}{1+\mathrm{d}^{3} \times \mathrm{c}} \\
& =\frac{192.17 \times 1.96 \times 0.00009076}{1+1.96^{3} \times 0.00009076} \\
M & =0.03
\end{aligned}
$$

Dengan menggunakan fungsi Goal Seek dengan aplikasi Microsoft Excel sebagai berikut :

$$
\begin{aligned}
& b\left(P-P_{s}\right)-\frac{1-2 \times b \times M}{2} \ln \left|\frac{(P+M)^{2}+N}{\left(P_{s}+M\right)^{2}+N}\right| \\
& -\frac{M+b N-b M^{2}}{\sqrt{N}}
\end{aligned}
$$$$
\left[\tan ^{-1}\left(\frac{P+M}{\sqrt{N}}\right)-\tan ^{-1}\left(\frac{P_{s}+M}{\sqrt{N}}\right)\right]
$$$$
=a\left(1+d^{2} e\right) \mathrm{L}
$$

$0.00007(455225.2-7200)$

$$
\begin{aligned}
& -\frac{1-2 \times 0.00007 \times 0.03}{2} x \\
& \ln \left|\frac{(455225.2+0.03)^{2}+3.35}{(7200+0.03)^{2}+3.35}\right|- \\
& \frac{0.03+0.00007 \times 3.35-0.00007 \times 0.03^{2}}{\sqrt{3.35}} x \\
& {\left[\tan ^{-1}\left(\frac{455225.2+0.03}{\sqrt{3.35}}\right)-\tan ^{-1}\left(\frac{7200+0.03}{\sqrt{3.35}}\right)\right]} \\
& =0.00459\left(1+(1.96)^{2} \times 0.00009076\right) \times 7152.23 \\
& 40.44=32.87
\end{aligned}
$$

Setelah di Goal Seek, perbandingannya menjadi sama:

$32.87=32.87$

Didapat BHCP setelah penambahan udara sebesar:

$\mathrm{BHCP}=356566 \mathrm{lb} / \mathrm{ft} 2$ atau $2476 \mathrm{psi}$

Jadi didapat BHCP pada rate injeksi lumpur 600 gpm dan rate injeksi udara 500 scfm yaitu 2476 psi dan kombinasi rate 
injeksi lumpur 600 gpm dan rate injeksi udara yang lain hasilnya dapat dilihat pada Tabel 3, Tabel 4 dan Tabel 5.

\section{Menghitung ECD}

$$
\begin{aligned}
\mathrm{ECD} & =\frac{\text { BHCP-14.696 }}{0.052 \times \mathrm{TVD}} \\
& =\frac{2476-14.696}{0.052 \times 7152.2} \\
\mathrm{ECD} & =6.62 \mathrm{ppg}
\end{aligned}
$$

Jadi didapat ECD pada rate injeksi lumpur 600 gpm dan rate injeksi udara 500 scfm yaitu $6.62 \mathrm{ppg}$ dan kombinasi rate injeksi lumpur $600 \mathrm{gpm}$ dan rate injeksi udara yang lain hasilnya dapat dilihat pada Tabel 6, Tabel 7 dan Tabel 8 .

Tabel 3. Hasil BHCP Trayek $12 \frac{1}{4}$ ،

\begin{tabular}{lcccccc}
\hline \multirow{2}{*}{ Qgo } & 100 & 500 & 1000 & 1500 & 2000 & 2400 \\
Q1 & SCFD & SCFD & SCFD & SCFD & SCFD & SCFD \\
\hline 600 GPM & $3054 \mathrm{psi}$ & $2476 \mathrm{psi}$ & $1854 \mathrm{psi}$ & $1358 \mathrm{psi}$ & $990 \mathrm{psi}$ & $764 \mathrm{psi}$ \\
$\mathbf{7 0 0}$ GPM & $3076 \mathrm{psi}$ & $2572 \mathrm{psi}$ & $2017 \mathrm{psi}$ & $1546 \mathrm{psi}$ & $1182 \mathrm{psi}$ & $946 \mathrm{psi}$ \\
$\mathbf{8 0 0}$ GPM & $3092 \mathrm{psi}$ & $2637 \mathrm{psi}$ & $2146 \mathrm{psi}$ & $1717 \mathrm{psi}$ & $1358 \mathrm{psi}$ & $1122 \mathrm{psi}$ \\
$\mathbf{9 0 0}$ GPM & $3105 \mathrm{psi}$ & $2709 \mathrm{psi}$ & $2250 \mathrm{psi}$ & $1840 \mathrm{psi}$ & $1506 \mathrm{psi}$ & $1283 \mathrm{psi}$ \\
\hline
\end{tabular}

Tabel 4. Hasil BHCP Trayek $9 \frac{5}{8}$ “

\begin{tabular}{lcccccc}
\hline \multicolumn{1}{c}{ Qgo } & 100 & 500 & 1000 & 1500 & 2000 & 2400 \\
Q1 & SCFD & SCFD & SCFD & SCFD & SCFD & SCFD \\
\hline 600 GPM & $3479 \mathrm{psi}$ & $2753 \mathrm{psi}$ & $1998 \mathrm{psi}$ & $1434 \mathrm{psi}$ & $965 \mathrm{psi}$ & $763 \mathrm{psi}$ \\
$\mathbf{7 0 0}$ GPM & $3510 \mathrm{psi}$ & $2901 \mathrm{psi}$ & $2236 \mathrm{psi}$ & $1675 \mathrm{psi}$ & $1209 \mathrm{psi}$ & $987 \mathrm{psi}$ \\
$\mathbf{8 0 0}$ GPM & $3532 \mathrm{psi}$ & $3003 \mathrm{psi}$ & $2415 \mathrm{psi}$ & $1896 \mathrm{psi}$ & $1485 \mathrm{psi}$ & $1209 \mathrm{psi}$ \\
$\mathbf{9 0 0}$ GPM & $3551 \mathrm{psi}$ & $3075 \mathrm{psi}$ & $2553 \mathrm{psi}$ & $2068 \mathrm{psi}$ & $1684 \mathrm{psi}$ & $1447 \mathrm{psi}$ \\
\hline
\end{tabular}

Tabel 5. Hasil BHCP Trayek $7 \frac{7}{8}$ ،

\begin{tabular}{lcccccc}
\hline & & & & & & \\
Q1 & 100 & 500 & 1000 & 1500 & 2000 & 2400 \\
& SCFD & SCFD & SCFD & SCFD & SCFD & SCFD \\
\hline 600 GPM & $4023 \mathrm{psi}$ & $3087 \mathrm{psi}$ & $2148 \mathrm{psi}$ & $1405 \mathrm{psi}$ & $978 \mathrm{psi}$ & $712 \mathrm{psi}$ \\
$\mathbf{7 0 0}$ GPM & $4071 \mathrm{psi}$ & $3313 \mathrm{psi}$ & $2489 \mathrm{psi}$ & $1810 \mathrm{psi}$ & $1327 \mathrm{psi}$ & $1017 \mathrm{psi}$ \\
$\mathbf{8 0 0}$ GPM & $4105 \mathrm{psi}$ & $3467 \mathrm{psi}$ & $2748 \mathrm{psi}$ & $2129 \mathrm{psi}$ & $1628 \mathrm{psi}$ & $1319 \mathrm{psi}$ \\
$\mathbf{9 0 0}$ GPM & $4129 \mathrm{psi}$ & $3584 \mathrm{psi}$ & $2956 \mathrm{psi}$ & $2386 \mathrm{psi}$ & $1894 \mathrm{psi}$ & $1606 \mathrm{psi}$ \\
\hline
\end{tabular}


Rial Dwi Martasari : Penentuan Injeksi Udara Optimum dalam Operasi Aerated Drilling pada Sumur Panas Bumi PT Air Drilling Associates

Jurnal Migasian, e-issn: 2615-6695 / p-issn: 2580-5258

Tabel 6. Hasil ECD Trayek $12 \frac{1}{4}$ ،

\begin{tabular}{lcccccc}
\hline \multicolumn{1}{c}{ Qgo } & 100 & 500 & 1000 & 1500 & 2000 & 2400 \\
& SCFD & SCFD & SCFD & SCFD & SCFD & SCFD \\
\hline $\mathbf{6 0 0 ~ G P M ~}$ & $8.17 \mathrm{ppg}$ & $6.62 \mathrm{ppg}$ & $4.95 \mathrm{ppg}$ & $3.61 \mathrm{ppg}$ & $2.62 \mathrm{ppg}$ & $2.01 \mathrm{ppg}$ \\
$\mathbf{7 0 0}$ GPM & $8.23 \mathrm{ppg}$ & $6.88 \mathrm{ppg}$ & $5.38 \mathrm{ppg}$ & $4.12 \mathrm{ppg}$ & $3.14 \mathrm{ppg}$ & $2.51 \mathrm{ppg}$ \\
$\mathbf{8 0 0} \mathbf{G P M}$ & $8.27 \mathrm{ppg}$ & $7.05 \mathrm{ppg}$ & $5.73 \mathrm{ppg}$ & $4.58 \mathrm{ppg}$ & $3.61 \mathrm{ppg}$ & $2.98 \mathrm{ppg}$ \\
$\mathbf{9 0 0}$ GPM & $8.31 \mathrm{ppg}$ & $7.25 \mathrm{ppg}$ & $6.01 \mathrm{ppg}$ & $4.91 \mathrm{ppg}$ & $4.01 \mathrm{ppg}$ & $3.41 \mathrm{ppg}$ \\
\hline
\end{tabular}

Tabel 7. Hasil ECD Trayek $9 \frac{5}{8}$ ،

\begin{tabular}{lcccccc}
\hline \multirow{2}{*}{ Qgo } & 100 & 500 & 1000 & 1500 & 2000 & 2400 \\
& SCFD & SCFD & SCFD & SCFD & SCFD & SCFD \\
\hline 600 GPM & $8.03 \mathrm{ppg}$ & $6.34 \mathrm{ppg}$ & $4.59 \mathrm{ppg}$ & $3.29 \mathrm{ppg}$ & $2.20 \mathrm{ppg}$ & $1.73 \mathrm{ppg}$ \\
$\mathbf{7 0 0}$ GPM & $8.10 \mathrm{ppg}$ & $6.69 \mathrm{ppg}$ & $5.15 \mathrm{ppg}$ & $3.85 \mathrm{ppg}$ & $2.77 \mathrm{ppg}$ & $2.25 \mathrm{ppg}$ \\
$\mathbf{8 0 0}$ GPM & $8.15 \mathrm{ppg}$ & $6.92 \mathrm{ppg}$ & $5.56 \mathrm{ppg}$ & $4.36 \mathrm{ppg}$ & $3.41 \mathrm{ppg}$ & $2.77 \mathrm{ppg}$ \\
$\mathbf{9 0 0}$ GPM & $8.19 \mathrm{ppg}$ & $7.09 \mathrm{ppg}$ & $5.88 \mathrm{ppg}$ & $4.76 \mathrm{ppg}$ & $3.87 \mathrm{ppg}$ & $3.32 \mathrm{ppg}$ \\
\hline
\end{tabular}

Tabel 8. Hasil ECD Trayek $7 \frac{7}{8}$ ،

\begin{tabular}{|c|c|c|c|c|c|c|}
\hline Qgo & $\begin{array}{c}100 \\
\text { SCFD }\end{array}$ & $\begin{array}{c}500 \\
\text { SCFD }\end{array}$ & $\begin{array}{c}1000 \\
\text { SCFD }\end{array}$ & $\begin{array}{c}1500 \\
\text { SCFD }\end{array}$ & $\begin{array}{c}2000 \\
\text { SCFD }\end{array}$ & $\begin{array}{c}2400 \\
\text { SCFD }\end{array}$ \\
\hline 600 GPM & $7.97 \mathrm{ppg}$ & $6.10 \mathrm{ppg}$ & $4.24 \mathrm{ppg}$ & $2.76 \mathrm{ppg}$ & $1.91 \mathrm{ppg}$ & $1.39 \mathrm{ppg}$ \\
\hline 700 GPM & $8.06 \mathrm{ppg}$ & $6.55 \mathrm{ppg}$ & $4.92 \mathrm{ppg}$ & $3.57 \mathrm{ppg}$ & $2.61 \mathrm{ppg}$ & $1.99 \mathrm{ppg}$ \\
\hline 800 GPM & $8.13 \mathrm{ppg}$ & $6.86 \mathrm{ppg}$ & $5.43 \mathrm{ppg}$ & $4.20 \mathrm{ppg}$ & $3.21 \mathrm{ppg}$ & $2.59 \mathrm{ppg}$ \\
\hline 900 GPM & $8.18 \mathrm{ppg}$ & $7.09 \mathrm{ppg}$ & $5.84 \mathrm{ppg}$ & $4.71 \mathrm{ppg}$ & $3.73 \mathrm{ppg}$ & $3.16 \mathrm{ppg}$ \\
\hline
\end{tabular}

\section{Menghitung Batas Efektif}

Hitung BHCP untuk ECD 5 ppg dan 7 ppg sebagai batas efektif penggunaan aerated drilling pada trayek $12 \frac{1}{4}$.

$$
\begin{array}{ll}
\text { Aerated Range } & =0.052 \times 5 \mathrm{ppg} \times \mathrm{TVD} \\
& =0.052 \times 5 \mathrm{ppg} \times 7152.23 \mathrm{ft} \\
\text { Aerated Range } & =1860 \mathrm{Psi} \\
\text { Aerated Range } & =0.052 \times 7 \mathrm{ppg} \times \mathrm{TVD} \\
& =0.052 \times 7 \mathrm{ppg} \times 7152.23 \mathrm{ft}
\end{array}
$$

Aerated Range $=2603 \mathrm{psi}$

Tabel 9. Hasil Batas Efektif

\begin{tabular}{cccc}
\hline \multirow{3}{*}{ Batas } & \multicolumn{3}{c}{ Trayek } \\
\cline { 2 - 4 } Efektif & $12 \frac{1}{4}$ & $9 \frac{5}{8}$ & $7 \frac{7}{8}$ \\
\hline $5 \mathrm{ppg}$ & $1860 \mathrm{psi}$ & $2158 \mathrm{psi}$ & $2516 \mathrm{psi}$ \\
$7 \mathrm{ppg}$ & $2603 \mathrm{psi}$ & $3021 \mathrm{psi}$ & $3523 \mathrm{psi}$ \\
\hline
\end{tabular}




\section{Grafik BHCP Terhadap Qgo}

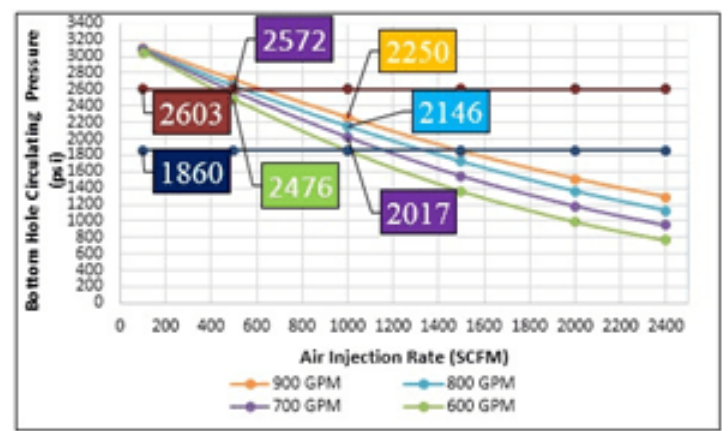

Grafik 1. BHCP Vs Qgo Trayek $12 \frac{1}{4}$ “،

Dari grafik 1 BHCP VS Qgo Trayek $12 \frac{1_{6}}{4}$ pada batasan ECD 5 pgg dengan BHCP 1860 psi dan 7 ppg dengan BHCP 2603 psi, dapat dilihat perbandingan volume lumpur dan udara yang direkomendasikan dapat digunakan. Pada volume lumpur 600 gpm, volume udara yang direkomendasikan yaitu 500 scfm menghasilkan BHCP sebesar 2476 psi. Pada volume lumpur 700 gpm, volume udara yang direkomendasikan yaitu 500 scfm menghasilkan BHCP sebesar 2572 psi dan 1000 scfm menghasilkan BHCP sebesar 2017 psi. Pada volume lumpur 800 gpm, volume udara yang direkomendasikan yaitu 1000 scfm menghasilkan BHCP sebesar 2146 psi. Pada volume lumpur 900 gpm, volume udara yang direkomendasikan yaitu 1000 scfm menghasilkan BHCP sebesar 2250 psi.

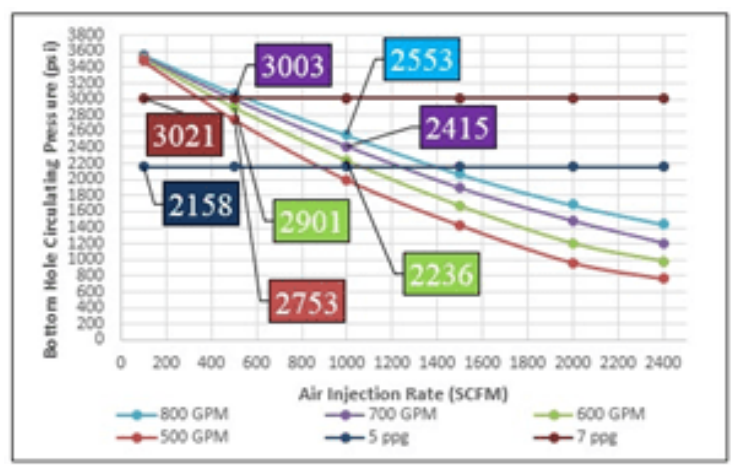

Grafik 2. BHCP Vs Qgo Trayek 9 $\frac{5}{8}$ ”
Dari grafik 2 BHCP VS Qgo Trayek $9 \frac{5}{8}$ " pada batasan ECD 5 pgg dengan BHCP 2158 psi dan 7 ppg dengan BHCP 3021 psi, dapat dilihat perbandingan volume lumpur dan udara yang direkomendasikan dapat digunakan. Pada volume lumpur $500 \mathrm{gpm}$, volume udara yang direkomendasikan yaitu 500 scfm menghasilkan BHCP sebesar 2753 psi. Pada volume lumpur 600 gpm, volume udara yang direkomendasikan yaitu 500 scfm menghasilkan BHCP sebesar 2901 dan 1000 scfm menghasilkan BHCP sebesar 2236 psi. Pada volume lumpur 700 gpm, volume udara yang direkomendasikan yaitu 500 scfm menghasilkan 3003 psi dan 1000 scfm menghasilkan BHCP sebesar 2415 psi. Pada volume lumpur 800 gpm, volume udara yang direkomendasikan yaitu 1000 scfm menghasilkan BHCP sebesar 2553 psi.

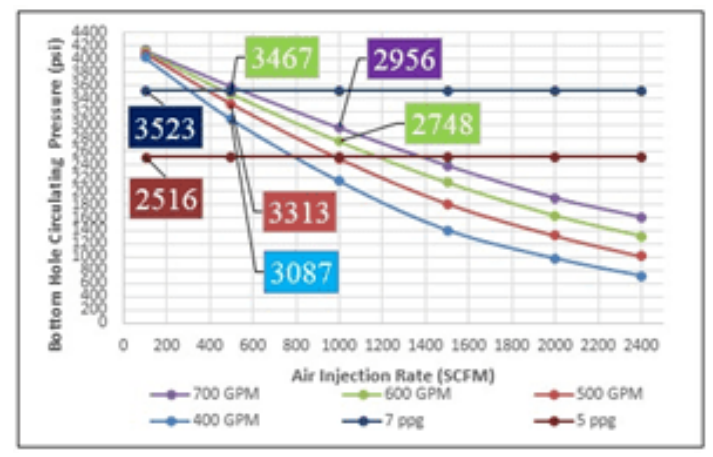

Grafik 3. BHCP Vs Qgo Trayek $7 \frac{7}{8}$ “

Dari grafik 3 BHCP VS Qgo Trayek 7-7, pada batasan ECD 5 pgg dengan BHCP 2516 psi dan 7 ppg dengan BHCP 3523 psi, dapat dilihat perbandingan volume lumpur dan udara yang direkomendasikan dapat digunakan. Pada volume lumpur 400 gpm, volume udara yang direkomendasikan yaitu 500 scfm menghasilkan BHCP sebesar 3087 psi. Pada volume lumpur 500 gpm, 
Rial Dwi Martasari : Penentuan Injeksi Udara Optimum dalam Operasi Aerated Drilling pada Sumur Panas Bumi PT Air Drilling Associates

Jurnal Migasian, e-issn: 2615-6695 / p-issn: 2580-5258

volume udara yang direkomendasikan yaitu $500 \mathrm{scfm}$ menghasilkan BHCP sebesar 3313 psi. Pada volume lumpur 600 gpm, volume udara yang direkomendasikan yaitu $500 \mathrm{scfm}$ menghasilkan BHCP sebesar 3467 psi dan 1000 scfm menghasilkan BHCP sebesar 2748 psi. Pada volume lumpur $700 \mathrm{gpm}$, volume udara yang direkomendasikan yaitu 1000 scfm menghasilkan BHCP sebesar 2956 psi.

\section{Pembahasan}

Dari grafik 1 BHCP VS Qgo Trayek $12 \frac{1}{4}$ “، pada batasan ECD 5 pgg dengan BHCP 1860 psi dan 7 ppg dengan BHCP 2603 psi, dapat dilihat perbandingan volume lumpur dan udara yang direkomendasikan dapat digunakan. Pada volume lumpur 600 gpm, volume udara yang direkomendasikan yaitu $500 \mathrm{scfm}$. Pada volume lumpur $700 \mathrm{gpm}$, volume udara yang direkomendasikan yaitu 500 scfm dan $1000 \mathrm{scfm}$. Pada volume lumpur 800 gpm, volume udara yang direkomendasikan yaitu $1000 \mathrm{scfm}$. Pada volume lumpur $900 \mathrm{gpm}$, volume udara yang direkomendasikan yaitu $1000 \mathrm{scfm}$.

Dari grafik 2 BHCP VS Qgo Trayek 9 $\frac{5}{8}$ " pada batasan ECD 5 pgg dengan BHCP 2158 psi dan 7 ppg dengan BHCP 3021 psi, dapat dilihat perbandingan volume lumpur dan udara yang direkomendasikan dapat digunakan. Pada volume lumpur 500 gpm, volume udara yang direkomendasikan yaitu $500 \mathrm{scfm}$. Pada volume lumpur $600 \mathrm{gpm}$, volume udara yang direkomendasikan yaitu 500 scfm dan 1000 scfm. Pada volume lumpur 700 gpm, volume udara yang direkomendasikan yaitu $500 \mathrm{scfm}$ dan 1000 scfm. Pada volume lumpur 800 gpm, volume udara yang direkomendasikan yaitu $1000 \mathrm{scfm}$.

Dari grafik 3 BHCP VS Qgo Trayek 7 $\frac{7}{8}$ “ pada batasan ECD 5 pgg dengan BHCP 2516 psi dan 7 ppg dengan BHCP 3523 psi, dapat dilihat perbandingan volume lumpur dan udara yang direkomendasikan dapat digunakan. Pada volume lumpur 400 gpm, volume udara yang direkomendasikan yaitu $500 \mathrm{scfm}$. Pada volume lumpur 500 gpm, volume udara yang direkomendasikan yaitu $500 \mathrm{scfm}$. Pada volume lumpur $600 \mathrm{gpm}$, volume udara yang direkomendasikan yaitu 500 scfm dan 1000 scfm. Pada volume lumpur 700 gpm, volume udara yang direkomendasikan yaitu $1000 \mathrm{scfm}$.

\section{KESIMPULAN}

Berdasarkan dari hasil pembahasan yang berjudul Penentuan Injeksi Udara Optimum Dalam Operasi Aerated Drilling Pada Sumur Panas Bumi, dapat ditarik kesimpulan yaitu kondisi digunakannya aerated drilling saat pemboran menembus formasi pada kedalaman $2180 \mathrm{~m}$ pada trayek $12 \frac{1}{4}$ ، , kedalaman $2530 \mathrm{~m}$ pada trayek $9 \frac{5}{8}$ " dan pada kedalaman $2950 \mathrm{~m}$ pada trayek $7 \frac{7}{8}$ “ yang dimana pada zona tersebut terdapat partial loss. Perbandingan volume injeksi lumpur dengan volume injeksi udara untuk aerated drilling pada sumur geothermal trayek $12 \frac{1}{4}$ “، yaitu Pada volume lumpur 600 gpm dengan volume udara $500 \mathrm{scfm}$. Pada volume lumpur 700 gpm dengan volume udara 500 scfm dan 1000 scfm. Pada volume lumpur 800 gpm dengan volume udara $1000 \mathrm{scfm}$. Pada volume lumpur 900 gpm, volume udara yang direkomendasikan yaitu 1000 scfm. Perbandingan volume injeksi lumpur dengan volume injeksi udara untuk 
aerated drilling pada sumur geothermal trayek 9 $\frac{5}{8}$ ", yaitu Pada volume lumpur 500 gpm dengan volume udara $500 \mathrm{scfm}$ dan 1000 scfm Pada volume lumpur 600 gpm dengan volume udara $500 \mathrm{scfm}$ dan 1000 scfm. Pada volume lumpur 700 gpm dengan volume udara $500 \mathrm{scfm}$ dan $1000 \mathrm{scfm}$. Pada volume lumpur $800 \mathrm{gpm}$, volume udara yang direkomendasikan yaitu 1000 scfm. Perbandingan volume injeksi lumpur dengan volume injeksi udara untuk aerated drilling pada sumur geothermal trayek $7 \frac{7}{8}$ “, yaitu Pada volume lumpur 400 gpm dengan volume udara $500 \mathrm{scfm}$. Pada volume lumpur $500 \mathrm{gpm}$ dengan volume udara yang $500 \mathrm{scfm}$. Pada volume lumpur 600 gpm dengan volume udara $500 \mathrm{scfm}$ dan $1000 \mathrm{scfm}$. Pada volume lumpur 700 gpm, volume udara yang direkomendasikan yaitu $1000 \mathrm{scfm}$.

\section{UCAPAN TERIMAKASIH}

Terimakasih kepada PT Air Drilling Associates telah memberikan kesempatan dan tempat yang disediakan serta ilmu yang telah dibagikan selama penelitian ini berjalan.

\section{DAFTAR PUSTAKA}

[1] Guo, Boyun, Ghalambor, Ali., Gas Volume Requirements for Underbalanced Drilling, PennWell, Oklahoma, 2002.

[2] Hussain, Rabia., Well Engineering \& Construction, Iran, 2002.

[3] Putra, I Made Budi Kesuma., Drilling Practice With Aerated Drilling Fluid: Indonesian and Icelandic Geothermal Field, United Nation University, Iceland, hal.1-7, 2008.

[4] Saptadji, Neni Miryani., Teknik Panas Bumi, ITB, Bandung, 2009.

[5] Sun, Kai., Pressure Requirements in Foam Drilling, University of Louisiana, Lafayette, hal. 1-6, 2003. 